\title{
High tea consumption diminishes salivary $17 \beta$-estradiol concentration in Polish women
}

\author{
Maria Kapiszewska $^{1}$, Malgorzata Miskiewicz ${ }^{1}$, Peter T. Ellison ${ }^{2}$, Inger Thune ${ }^{3,4}$ and Grazyna Jasienska ${ }^{5,6}$ \\ ${ }^{1}$ Department of General Biochemistry, Faculty of Biotechnology, Jagiellonian University, Gronostajowa 7, 30-387 Kraków, Poland \\ ${ }^{2}$ Department of Biological Anthropology, Harvard University, Cambridge, MA 02138, USA \\ ${ }^{3}$ Institute of Community Medicine, University of Tromso, Tromso, Norway \\ ${ }^{4}$ Ulleval University Hospital, Oslo, Norway \\ ${ }^{5}$ Department of Epidemiology and Population Studies, Institute of Public Health, Jagiellonian University, 31-531 Kraków, Poland \\ ${ }^{6}$ Radcliffe Institute for Advanced Study, Harvard University, Cambridge, MA 02138, USA
}

(Received 16 August 2005 - Revised 6 January 2006 - Accepted 19 January 2006)

\begin{abstract}
We hypothesized that among reproductive-age women consuming large quantities of tea, the production of estradiol would be suppressed. It has been shown that catechins and theaflavines, the major constituents of tea, inhibit aromatase, an enzyme which catalyses the conversion of androgens to oestrogens. Our study included Polish women living in urban $(n 61)$ and rural $(n$ 48) areas. Women collected daily saliva samples for one complete menstrual cycle and filled out dietary questionnaires. Saliva samples were analysed by RIA for concentration of 17ß-estradiol (E2). Women with high (above the median) average daily consumption of black tea had reduced levels of salivary E2 in comparison with women who drank less black tea (below the median). This effect was observed within the whole study group, as well as separately within urban $(P=0.0006)$ and rural $(P=0.013)$ groups. High intake of the sum of subclasses of tea catechins and epigallocatechin gallate, assessed using the United States Department of Agriculture database (http://www.nal.usda.gov), was also associated with lower concentrations of E2 within all women $(P=0.01$ and $P=0.0001$, respectively) and within the urban group $(P=0.0001$ and $P=0.004$, respectively). Similar relationships were observed between the sum of subclasses of theaflavines and thearubigines and E2 levels for the whole group $(P=0 \cdot 002)$ and for urban women $(P=0 \cdot 02)$. Women with high consumption of tea had lower levels of $\mathrm{E} 2$ concentration throughout the entire menstrual cycle. These results may have implications for reducing hormone-related cancer risk by a relatively easy dietary intervention.
\end{abstract}

Catechins: Epigallocatechin 3-gallate: 17ß-Estradiol: Tea: Theaflavines

Changes in lifestyles and dietary habits in the post-industrial era can dramatically influence metabolism and the level of sex-steroid hormones (Ellison \& Lager, 1986; Jasienska et al. 2000, 2005, 2006; Wenger, 2004). It has been suggested that prolonged exposure to oestrogens during the life span due to early menarche, late menopause, lower parity and environmental oestrogenic toxins may be responsible for the increased rate of breast cancer (Verkasalo et al. 2001; Liu et al. 2004; Zografos et al. 2004). A diet rich in flavonoids and isoflavones, in particular, can decrease circulating oestrogen levels as well as menstrual cycle length ( $\mathrm{Lu}$ et al. 1996; Kumar et al. 2002). Furthermore, epidemiological data mainly from Asian countries indicate that high consumption of soya products containing an abundant amount of these compounds is inversely correlated with colon carcinoma and hormone-related cancers (Gittes, 1991; Lee et al. 1991; Seow et al. 1998; Wu et al. 2000). Soyabean products are consumed much less frequently in European countries than in Asia. The intake of foods containing isoflavonoids is almost negligible in the typical Polish diet, although flavan-3ols, the major constituents in tea, are consumed in large quantity. These flavonoids not only seem to decrease estradiol levels but also exhibit chemopreventive effects against breast cancer (Park $\&$ Surh, 2004). The inhibitory impact of tea constituents like catechins and theaflavines on aromatase, an enzyme involved in the final step of oestrogen production, is likely responsible for this preventive effect through modulation of circulating oestrogen levels (Chen et al. 2002; Satoh et al. 2002; Way et al. 2004). Since black tea, and to a lesser extent green tea, is consumed frequently in Poland, the Polish population provides an ideal context for investigating the potential relationship between tea consumption and estradiol levels. We studied healthy young women during one full menstrual cycle to investigate the relationship between salivary $17 \beta$ estradiol levels and the daily intake of: (1) black tea, (2) black and green tea together or 'total' tea, (3) the two major

Abbreviations: CAT, sum of six subclasses of catechins: (-)-epicatechin, (-)-epicatechin 3-gallate, (-)-epigallocatechin, (-)-EGCG, (+)-catechin and (+)gallocatechin; EGCG, epigallocatechin 3-gallate; E2, 17 $\beta$-estradiol; ThF, sum of four subclasses of theaflavines: theaflavine 3-gallate, theaflavines $3^{\prime}$-gallate, theaflavine $3,3^{\prime}$-digallate and thearubigins.

* Corresponding author: Dr Maria Kapiszewska, fax +48 12262 2174, email mkapisz@if.uj.edu.pl 
groups of constituents in tea, namely theaflavines and catechins, and (4) epigallocatechin 3-gallate (EGCG), the most biologically active compound.

\section{Materials and methods}

\section{Study design and participants}

Participants of the study were Polish women living in urban ( $n$ 61 ) and rural ( $n$ 48) areas. During the period from June 2001 to June 2003, urban women were recruited for the study through newspaper and television advertisements, while rural women were recruited through their parish. Women were selected for participation if they met the following criteria: age between 24 and 36 years, regular menstrual cycles, no fertility problems, no gynecological or chronic disorders (i.e. diabetes, hypo/hyperthyroidism), not taking any hormonal medication or using hormonal contraception, and not being pregnant or lactating for 6 months before recruitment. Subjects' body weight, height and body fat (by bioimpedance) were measured by a trained anthropologist. A general questionnaire (self-administered or through an interview) was used to collect information on education, reproductive history and past use of hormonal medication, tobacco and alcohol. Physical activity was assessed based on a physical activity $\log$ completed daily by each subject during the menstrual cycle (Jasienska et al. 2006).

\section{Ethical consideration}

The study protocol was reviewed and approved by the Jagiellonian University Medical College Ethics Committee.

\section{Hormone analysis}

Women collected morning saliva samples daily for one entire menstrual cycle. Saliva samples for $20 \mathrm{~d}$ of each cycle (reverse cycle days -5 to -24 ) were analysed for $17 \beta$-estradiol (E2) concentration using an ${ }^{125}$ I-based RIA kit (\#39 100; Diagnostic Systems Laboratories, Webster, TX, USA) along with published modifications to the manufacturer's protocol (Jasienska et al. 2004). The sensitivity of the estradiol assay was $4 \mathrm{pmol} / \mathrm{l}$. The average intra-assay variability was $9 \%$ and the inter-assay variability ranged from $23 \%$ for lower values $(15 \mathrm{pmol} / \mathrm{l})$ to $13 \%$ for higher values $(50 \mathrm{pmol} / \mathrm{l})$. Prior to statistical analyses, all cycles were aligned following published methods (Lipson \& Ellison, 1996) based on identification of the E2 drop at mid-cycle (day 0), which provides a reasonable estimate of the day of ovulation. The E2 values for 18 consecutive days from each cycle aligned on day 0 were used in data analyses.

\section{Dietary assessment}

Subjects were trained to estimate the volume of tea by using a photographic album identifying the size of a cup (Album of Food; Food and Nutrition Institute, Warsaw, Poland), to fill out the food diary questionnaire, and to record as much information about the type of tea and its preparation as possible. The majority of participants in our study used one teabag per cup of hot water with short brewing time. Seven food diary questionnaires were filled out by each participant during the menstrual cycle and the data were entered into a computer. A specially written computer program was used to estimate the daily intake of a particular class of polyphenols for each participant based on merging the average consumption of a particular type of tea with the flavonoid content of the tea, expressed as $\mathrm{mg} / 100 \mathrm{ml}$ tea infusion standardized to $1 \%$ infusion (as consumed) by the United States Department of Agriculture (2003) database. These standardized values were calculated using the weight of the teabag (or loose tea leaves) used to make the infusion. Adjustment for brewing time was not necessary as most tea flavonoids are extracted into the infusion after only short brewing times and do not increase substantially with extended duration of brewing (Hertog et al. 1993; Arts et al. 2000).

The amount of the two main groups of constituents in tea was calculated. The first group contained the sum of six subclasses of catechins (abbreviated to CAT): (-)-epicatechin, (-)-epicatechin 3-gallate, (-)-epigallocatechin, (-)-EGCG, $(+)$-catechin and $(+)$-gallocatechin. The second group contained the sum of four subclasses of theaflavines (abbreviated to $\mathrm{ThF}$ ): theaflavine 3 -gallate, theaflavine $3^{\prime}$-gallate, theaflavine 3,3'-digallate and thearubigins.

\section{Statistical analysis}

Women were divided into two groups based on their consumption level of black tea, their 'total' tea consumption (black and green), CAT and ThF intake, and EGCG intake. Women with intake levels above the median value for each of these tea products were classified as the 'high consumption' group and women with intake levels below the median value were classified as the 'low consumption' group. We used two-sided $t$ tests, separately for urban and rural women, to test for statistical differences in age, tobacco smoking, alcohol consumption, anthropometric and body composition variables, and mean physical activity between groups with low and high consumption of 'total' tea.

The effects of consumption of 'total' tea on E2 levels were then tested by factorial, three-way ANOVA analysis. The division into low and high consumption groups was used as one factor, the place of residence (urban or rural) as the second factor, and day of the menstrual cycle (with eighteen levels) as the third factor. The ANOVA was followed by contrast analyses; an $\alpha$ level of 0.025 (with Bonferroni correction) was used to indicate statistical significance. Similarly structured ANOVA analyses were also performed for the intake of black tea, CAT and ThF, and EGCG. To control for the potentially confounding effect of nutritional status, a four-way ANOVA analysis was performed with BMI as an additional factor in the model for 'total' tea consumption.

\section{Results}

\section{Characteristics of studied women}

Urban women characterized by low and high consumption of 'total' tea did not show statistically significant differences in age, age at menarche, first birth, number of children, smoking, drinking, physical activity and anthropometric variables (Table 1). Among rural women, however, those with low 
Table 1. Characteristics of the study groups*

\begin{tabular}{|c|c|c|c|c|c|c|c|c|c|c|}
\hline & \multicolumn{4}{|c|}{ Urban } & \multirow[b]{3}{*}{$P$ value } & \multicolumn{4}{|c|}{ Rural } & \multirow[b]{3}{*}{$P$ value } \\
\hline & \multicolumn{2}{|c|}{$\begin{array}{l}\text { Low consump- } \\
\quad \text { tion }(n 26)\end{array}$} & \multicolumn{2}{|c|}{$\begin{array}{l}\text { High consump- } \\
\text { tion (n 35) }\end{array}$} & & \multicolumn{2}{|c|}{$\begin{array}{l}\text { Low consump- } \\
\text { tion }(n 27)\end{array}$} & \multicolumn{2}{|c|}{$\begin{array}{l}\text { High consump- } \\
\text { tion }(n 21)\end{array}$} & \\
\hline & Mean & SD & Mean & SD & & Mean & SD & Mean & SD & \\
\hline Age (years) & 29.5 & 3.05 & $30 \cdot 0$ & 3.39 & 0.55 & $29 \cdot 7$ & 3.59 & $28 \cdot 9$ & 3.82 & 0.51 \\
\hline Self-reported age of menarche (years) & $12 \cdot 8$ & $1 \cdot 17$ & $13 \cdot 2$ & 1.6 & 0.32 & $13 \cdot 5$ & $1 \cdot 19$ & $13 \cdot 6$ & $1 \cdot 2$ & 0.7 \\
\hline Number of children & 0.7 & 0.84 & 0.5 & 0.85 & 0.35 & $1 \cdot 8$ & 1.51 & 1.4 & 1.63 & 0.4 \\
\hline Body height $(\mathrm{cm})$ & $162 \cdot 6$ & $5 \cdot 84$ & $164 \cdot 9$ & $6 \cdot 11$ & 0.15 & $161 \cdot 6$ & $5 \cdot 11$ & $157 \cdot 2$ & $5 \cdot 49$ & 0.01 \\
\hline Body weight (kg) & $61 \cdot 0$ & $10 \cdot 7$ & $58 \cdot 1$ & $8 \cdot 15$ & 0.34 & $66 \cdot 1$ & $12 \cdot 36$ & $56 \cdot 9$ & $8 \cdot 34$ & 0.01 \\
\hline $\mathrm{BMI}\left(\mathrm{kg} / \mathrm{m}^{2}\right)$ & $23 \cdot 0$ & $3 \cdot 32$ & 21.6 & $2 \cdot 75$ & 0.07 & $25 \cdot 3$ & 4.42 & 23.0 & 3.05 & 0.08 \\
\hline Body fat $(\%)$ & $27 \cdot 0$ & $7 \cdot 7$ & 24.9 & $6 \cdot 32$ & 0.25 & $30 \cdot 2$ & $6 \cdot 53$ & $26 \cdot 0$ & $7 \cdot 63$ & 0.06 \\
\hline Length of menstrual cycle (d) & 29.5 & $4 \cdot 73$ & 28.5 & 3.45 & 0.37 & $27 \cdot 7$ & $3 \cdot 0$ & $27 \cdot 6$ & $2 \cdot 39$ & 0.93 \\
\hline Physical activity (MET-h/d & $7 \cdot 2$ & 1.4 & $7 \cdot 6$ & $2 \cdot 0$ & 0.33 & $11 \cdot 6$ & 3.41 & $10 \cdot 7$ & $2 \cdot 87$ & 0.34 \\
\hline Smoking (cigarettes/d) & $1 \cdot 6$ & $4 \cdot 55$ & $0 \cdot 7$ & 2.54 & 0.35 & $2 \cdot 7$ & $5 \cdot 15$ & $1 \cdot 3$ & 3.0 & 0.33 \\
\hline
\end{tabular}

* Division into the low and high consumption groups is based on the median consumption of 'total' tea (sum of black and green).

$\dagger P$ values are derived from two-sided $t$ tests, separately for urban and rural women.

$\ddagger$ Metabolic equivalent (MET) is the ratio of the work metabolic rate to the resting metabolic rate. One MET is defined as $1 \mathrm{kcal} / \mathrm{kg}$ per $\mathrm{h}$ (Ainsworth et al. 2000).

'total' tea consumption were significantly taller and heavier than women with high 'total' tea consumption, although differences in other characteristics were not statistically significant (Table 1).

We estimated the amount and type of tea consumed as well as the amount of CAT and ThF, the two main subclasses of tea polyphenols, from 798 questionnaires filled out by the women participating in our study. All the study participants drank black tea; the mean daily intake was $473 \mathrm{ml}$. In contrast, green tea was consumed by only twenty-one participants. The mean daily intake of both black and green tea combined was $499 \mathrm{ml}$.

\section{Estradiol and black tea consumption}

Within both the urban and rural women, the group with high (above the median) consumption of black tea had a lower mean estradiol level than the group with low (below the median) black tea consumption ( $F$ 17.2, $P=0 \cdot 0001)$. For urban women, mean E2 levels were 21.7 and $18.8 \mathrm{pmol} / \mathrm{l}$ for the low and high consumption groups, respectively
$(P=0 \cdot 0006)$. For rural women, mean E2 levels were 18.4 and $16 \cdot 1 \mathrm{pmol} / \mathrm{l}$ for the low and high consumption groups, respectively $(P=0 \cdot 01$; Table 2$)$.

To test whether ThF, the main constituent of black tea, was responsible for this effect, we analysed whether groups of women who differed in ThF intake had different E2 levels. We found that women with high consumption of $\mathrm{ThF}$ had lower levels of E2 than women with low consumption of ThF ( $F$ 9.24, $P=0.002$ ). Contrast analyses showed that the difference in $\mathrm{E} 2$ levels between the low and high consumption groups was statistically significant within urban women $(P=0.02)$ but not rural women $(P=0.04)$.

\section{Estradiol and 'total' tea consumption}

'Total' tea consumption also showed a statistically significant relationship with E2 levels ( $F$ 16.96, $P=0 \cdot 0001)$. Within urban women, those with high 'total' tea consumption had reduced E2 concentration compared to women with low 'total' tea consumption ( $F 58 \cdot 1, P=0 \cdot 0001$; Fig. 1). Such a

Table 2. Mean levels of salivary $17 \beta$-estradiol (in pmol/l) for groups of urban and rural women characterized by low and high (below and above median) consumption of 'total' tea (sum of black and green), black tea and constituents*

\begin{tabular}{|c|c|c|c|c|c|c|c|c|c|c|}
\hline & \multicolumn{4}{|c|}{ Urban } & \multirow[b]{3}{*}{$P$ value $\dagger$} & \multicolumn{4}{|c|}{ Rural } & \multirow[b]{3}{*}{$P$ value } \\
\hline & \multicolumn{2}{|c|}{$\begin{array}{c}\text { Low } \\
\text { consumption }\end{array}$} & \multicolumn{2}{|c|}{$\begin{array}{c}\text { High } \\
\text { consumption }\end{array}$} & & \multicolumn{2}{|c|}{$\begin{array}{c}\text { Low } \\
\text { consumption }\end{array}$} & \multicolumn{2}{|c|}{$\begin{array}{c}\text { High } \\
\text { consumption }\end{array}$} & \\
\hline & Mean & SD & Mean & SD & & Mean & $\mathrm{SD}$ & Mean & SD & \\
\hline 'Total' tea & 23.9 & $16 \cdot 75$ & $18 \cdot 0$ & 11.74 & 0.0001 & $17 \cdot 0$ & $10 \cdot 48$ & $18 \cdot 0$ & $12 \cdot 17$ & 0.34 \\
\hline Black tea & $21 \cdot 7$ & $16 \cdot 29$ & $18 \cdot 8$ & $12 \cdot 6$ & 0.0006 & $18 \cdot 4$ & $11 \cdot 26$ & $16 \cdot 1$ & $10 \cdot 88$ & 0.013 \\
\hline CAT & $21 \cdot 2$ & $16 \cdot 75$ & $18 \cdot 9$ & 11.95 & 0.004 & $17 \cdot 2$ & $11 \cdot 17$ & $16 \cdot 7$ & $10 \cdot 89$ & 0.45 \\
\hline ThF & 20.9 & $16 \cdot 73$ & $19 \cdot 1$ & $12 \cdot 19$ & 0.02 & 17.86 & $11 \cdot 35$ & $15 \cdot 9$ & 9.7 & 0.04 \\
\hline EGCG & $23 \cdot 2$ & 18.07 & $19 \cdot 0$ & $11 \cdot 76$ & 0.0001 & $17 \cdot 39$ & 11.05 & $16 \cdot 2$ & $10 \cdot 78$ & 0.17 \\
\hline
\end{tabular}

CAT, sum of six subclasses of catechins: $(-)$-epicatechin, $(-)$-epicatechin 3-gallate, $(-)$-epigallocatechin, $(-)$-EGCG, $(+)$-catechin and $(+)$-gallocatechin; EGCG, epigallocatechin 3-gallate; ThF, sum of four subclasses of theaflavines: theaflavine 3-gallate, theaflavine $3^{\prime}$-gallate, theaflavine $3,3^{\prime}$-digallate and thearubigins.

${ }^{*}$ For details of procedures, see p. 990

$\dagger P$ values are derived from the contrast analyses following the ANOVA analyses. 


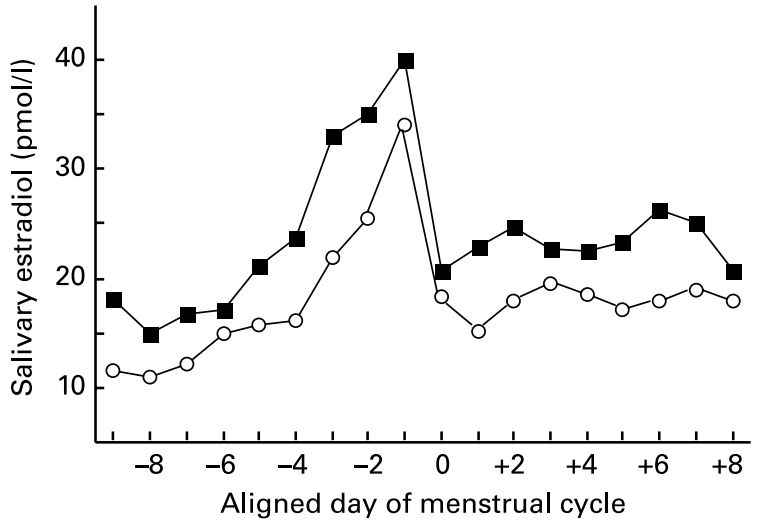

Fig. 1. Estradiol profiles in groups of urban women with low (ם) and high (O) consumption of 'total' (black and green) tea. Division into groups is based on median consumption. For details of procedures, see p. 990. Values are means ( $\mathrm{Cl}$ omitted for clarity).

relationship was not evident for the rural women $(F$ 0.91, $P=0 \cdot 34)$. Urban women drank more 'total' tea than rural women, mainly because more urban women drank green tea compared to the rural women (Table 3 ). Since higher consumption of 'total' tea significantly enhanced the amount of CAT consumed, we analysed the influence of CAT intake above and below the median value on estradiol profiles. For urban women, daily CAT intake delivered from both kinds of tea showed a statistically significant association with E2 levels ( $F$ 8.37, $P=0 \cdot 004$; Fig. 2). For rural women, daily CAT intake above and below the median did not show a statistically significant association with E2 levels ( $F$ 0.57, $P=0.45)$.

\section{Estradiol and epigallocatechin 3-gallate consumption}

Since EGCG is the dominant and most bioactive compound in tea in terms of its inhibitory effect on aromatase activity, we tested whether groups of women who differed in EGCG intake showed different E2 levels. For urban women, E2 levels were significantly lower $(F 25.46, P=0.0001)$ for the group with high EGCG intake (above the median value) compared to the group with low EGCG intake (below the median value; Fig. 3). No difference was detected for the rural women (F 1.91, $P=0 \cdot 17$ ).

\section{BMI and physical activity as additional factors}

The relationship between 'total' tea consumption and E2 remained statistically significant after controlling for the potentially confounding effect of BMI ( $F$ 31.55, $P=0.0001)$. The relationship between BMI and E2 levels was not statistically significant $(F 3 \cdot 1, P=0.05)$. Within the urban women, the low 'total' tea consumption group had higher levels of E2 after controlling for BMI than the high 'total' tea consumption group $(F$ 85.06, $P=0.0001)$. Within the rural women, differences in E2 between the low and high 'total' tea consumption groups remained statistically non-significant after including BMI in the model $(F$ 0.009, $P=0.92$ ).

In order to control for the potentially confounding effect of physical activity on estradiol levels we performed three-way factorial ANOVA analyses, separately for the urban and rural women. Division into low and high 'total' tea consumption groups was used as one factor, day of the menstrual cycle as the second factor and division into tertiles of physical activity (following a published method by Jasienska et al. 2006) as the third factor. In urban women, the relationship between 'total' tea consumption and E2 level remained statistically significant ( $F$ 49.8, $P=0.0001$ ). We also found a statistically significant inverse relationship between physical activity and E2 levels ( $F 4.98, P=0.007$ ) confirming our previously published results (Jasienska et al. 2006). A similar relationship was observed in rural women as well: while physical activity had an effect on E2 levels ( $F 12.57, P=0.0001)$, there was also a statistically significant inverse relationship between 'total' tea consumption and $\mathrm{E} 2$ levels ( $F 5 \cdot 5, P=0 \cdot 02$ ).

\section{Discussion}

Endocrine regulation is very susceptible to lifestyle factors, in particular diet and environmental modification. For example, high levels of physical activity (Ellison \& Lager, 1986; Jasienska \& Ellison, 1998, 2004; Jasienska \& Thune, 2001; Willer, 2003; Wenger, 2004; Jasienska et al. 2006) or certain dietary habits, such as enhanced consumption of soya products (Cassidy et al. 1994; Nagata et al. 1998; Wu et al. 2000;

Table 3. Consumption of 'total' tea (sum of black and green), black tea and constituents in groups of women characterized by low and high (below and above median) consumption*

\begin{tabular}{|c|c|c|c|c|c|c|c|c|c|c|c|c|}
\hline & \multicolumn{4}{|c|}{ All women } & \multicolumn{4}{|c|}{ Urban } & \multicolumn{4}{|c|}{ Rural } \\
\hline & \multicolumn{2}{|c|}{$\begin{array}{c}\text { Low } \\
\text { consumption }\end{array}$} & \multicolumn{2}{|c|}{$\begin{array}{c}\text { High } \\
\text { consumption }\end{array}$} & \multicolumn{2}{|c|}{$\begin{array}{c}\text { Low } \\
\text { consumption }\end{array}$} & \multicolumn{2}{|c|}{$\begin{array}{c}\text { High } \\
\text { consumption }\end{array}$} & \multicolumn{2}{|c|}{$\begin{array}{c}\text { Low } \\
\text { consumption }\end{array}$} & \multicolumn{2}{|c|}{$\begin{array}{c}\text { High } \\
\text { consumption }\end{array}$} \\
\hline & Mean & SD & Mean & SD & Mean & SD & Mean & SD & Mean & SD & Mean & SD \\
\hline 'Total' tea (ml) & 252.5 & $127 \cdot 03$ & $778 \cdot 8$ & 348.5 & 243.6 & $136 \cdot 7$ & $846 \cdot 8$ & 382.92 & $261 \cdot 0$ & 118.98 & 621.5 & $177 \cdot 0$ \\
\hline Black tea $(\mathrm{ml})$ & $233 \cdot 3$ & 111.09 & $712 \cdot 1$ & 328.43 & $236 \cdot 9$ & $11 \cdot 39$ & $781 \cdot 2$ & $360 \cdot 15$ & $229 \cdot 9$ & $113 \cdot 0$ & $570 \cdot 04$ & $190 \cdot 23$ \\
\hline $\mathrm{ThF}(\mathrm{mg})$ & $197 \cdot 1$ & $76 \cdot 24$ & $561 \cdot 7$ & $235 \cdot 72$ & $191 \cdot 8$ & 79.94 & $638 \cdot 4$ & $258 \cdot 0$ & $202 \cdot 8$ & $73 \cdot 35$ & $428 \cdot 4$ & 97.54 \\
\hline EGCG (mg) & $20 \cdot 9$ & $14 \cdot 12$ & $120 \cdot 1$ & 89.99 & $20 \cdot 0$ & $14 \cdot 12$ & $131 \cdot 2$ & 87.56 & $21 \cdot 7$ & $13 \cdot 88$ & 98.0 & 93.18 \\
\hline
\end{tabular}

CAT, sum of six subclasses of catechins: (-)-epicatechin, (-)-epicatechin 3-gallate, (-)-epigallocatechin, (-)-EGCG, (+)-catechin and (+)-gallocatechin; EGCG, epigallocatechin 3-gallate; ThF, sum of four subclasses of theaflavines: theaflavine 3-gallate, theaflavine $3^{\prime}$-gallate, theaflavine $3,3^{\prime}$-digallate and thearubigins.

${ }^{*}$ For details of procedures, see p. 990. 


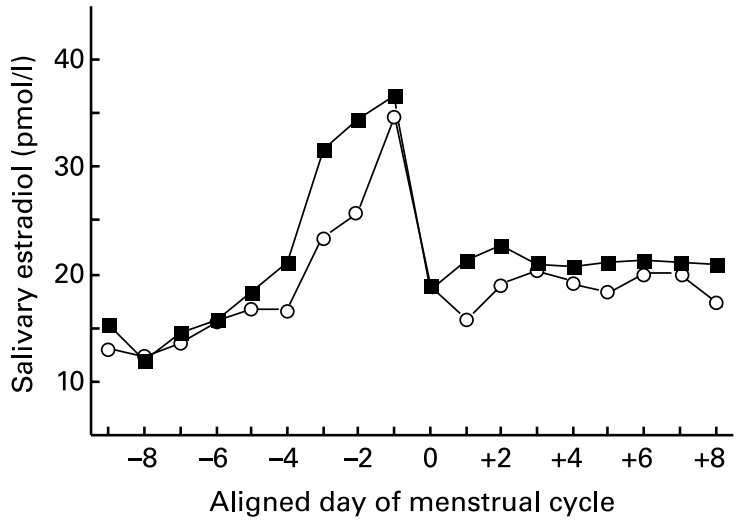

Fig. 2. Estradiol profiles in groups of urban women with low ( $\square$ ) and high $(O)$ consumption of black tea. Division into groups is based on median consumption. For details of procedures, see p. 990. Values are means $(\mathrm{Cl}$ omitted for clarity).

Kumar et al. 2002) can lower levels of sex steroid hormones in women. Based on repeated observations of higher oestrogen levels in cancer tissue (for a review see Mueck et al. 2002), a reduction in estradiol levels may modify the risk of cancer. Since the incidence of cancer is related to the DNAdamaging activity of carcinogens, the association between E2 concentration in circulation and the extent of DNA damage seems to implicate estradiol as a reliable indicator of the risk of cancer (Key et al. 2002; Kapiszewska et al. 2005).

Localized oestrogen levels are determined by the enzyme CYP19, the aromatase which catalyses the conversion of androgens, including androstendione and testosterone, to oestrogens, including estrone and estradiol (Conley \& Hinshelwood, 2001). Thus, the selective inhibition of oestrogen biosynthesis can be achieved through the inhibition of aromatase (Chen et al. 2002). Recently, a few aromatase inhibitors have been developed for use in cancer therapy (Joensuu et al. 2005). The naturally occurring flavonoids were shown to inhibit aromatase and other steroidogenic enzymes as well as modulate oestrogen metabolism through their ability to bind with oestrogen receptors (Rosenberg Zand et al. 2002). Therefore, flavonoids, the most abundant compounds in

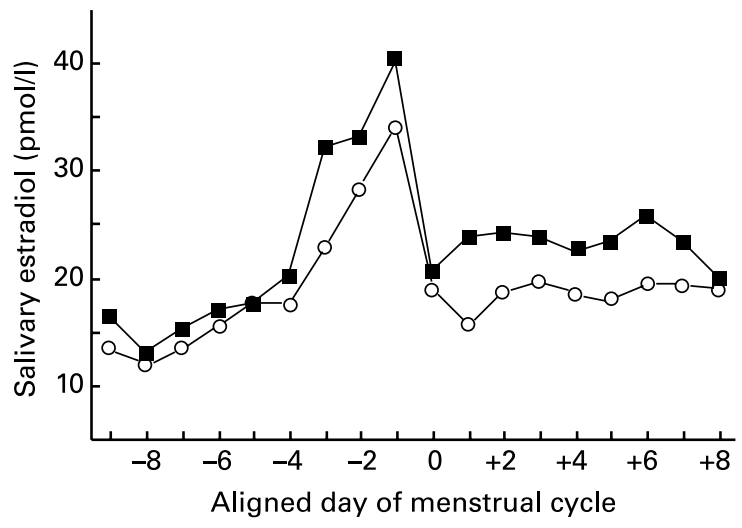

Fig. 3. Estradiol profiles in groups of urban women with low $(\square)$ and high $(\bigcirc)$ consumption of epigallocatechin 3-gallate (EGCG). Division into groups is based on median consumption. For details of procedures, see p. 990. Values are means $(\mathrm{Cl}$ omitted for clarity). plant foods such as fruits and vegetables, and certain beverages, including tea, wine, beer and juices, seem to be good candidates for shifting overall hormonal levels. Tea is a potent source of flavonoids in the diet, with levels approaching $200 \mathrm{mg} /$ cup for a typical brew of black tea (Lakenbrink et al. 2000).

The most extensively studied flavonoids, in terms of their influence on steroid metabolism, have been genistein and active isoflavone, widely present in soya products, and epigallocatechin gallate, derived from tea. Since black tea, as opposed to soya products, remains commonly consumed throughout Poland, the Polish population seems to be an appropriate group for studying the association between tea intake, along with its constituents, and E2 levels in women. In addition, the differences in lifestyle between rural and urban areas in Poland led us to analyse this relationship for women living in both types of region in Poland. Different lifestyles may affect the developmental conditions for women growing up in these regions, as suggested by the relatively later age at menarche and lower final body height for rural women compared to urban women (Laska-Mierzejewska, 1995; Bielicki \& Szklarska, 1999; Laska-Mierzejewska \& Olszewska, 2004). Lifestyle differences may influence the reproductive physiology, including hormonal metabolism, of adult women as well.

A popular habit in Poland is to drink tea at the workplace a few times a day, especially among urban, white-collar workers. Recently, the consumption of green tea has been promoted by the media and become more common, especially among well-educated people. This trend is similar to that described for the Netherlands (Hertog et al. 1993). Nonetheless, our ongoing research may be the last opportunity to study the effects of drinking tea, since transformation of the political system and the development of a free market in Poland are associated with replacing the habit of drinking tea with drinking carbonated soft drinks.

In our study, the average amount of black tea consumed was significantly higher than the average amount of green tea, as expected. When we analysed the association between salivary E2 levels during one menstrual cycle and tea intake, we found a statistically significant lowering effect on E2 for the sum of black and green tea intake for urban but not rural women. This difference may be related to the higher consumption of green tea by urban women. Even a small amount of green tea increased the CAT intake in our study subjects, as green tea contains threefold more catechins than black tea. It has been shown that the plasma level of CAT after the consumption of green tea is higher than after consumption of black tea (Lee et al. 2000) and also that the bioavailability of the subclasses of CAT differs (Rietveld \& Wiseman, 2003).

We tested the association between estradiol levels and the intake of ThF and CAT by comparing groups of women whose average intake was above and below the median values. Both CAT and ThF possess strong aromatase inhibitory activity (Park \& Surh, 2004; Way et al. 2004). We found a statistically significant lowering effect of $\mathrm{ThF}$ on estradiol levels for the total group of women in our study and, again, for the urban but not rural group of women.

The most biologically active compound among the CAT subclasses, EGCG, makes up more than $50 \%$ of the catechins 
found in green tea. Its biological effect is also the strongest. When administered orally to rats, EGCG induces the reduction of sex steroid concentrations due to the inhibition of aromatase activity (Satoh et al. 2002). In our study, the estradiol profiles of urban women suggest that high EGCG intake from tea is associated with reduced E2 levels in the luteal phase of the menstrual cycle but not in the follicular phase (Fig. 3). This lowering effect during the luteal phase may point to the important chemopreventive activity of EGCG, since breast cells are more proliferative during the luteal phase than the follicular phase (Nagamani et al. 1979; Lu et al. 2000). In light of the present finding, it would be interesting to evaluate the association between estradiol concentrations and tea intake separately for the follicular and luteal phase in the future.

A study of aromatase isolated from the microsomes of rat ovarian and human placental tissue (Way et al. 2004) indicates a dose-dependent relationship between EGCG and E2 in that only the presence of EGCG above a certain level exerts an inhibitory effect. In addition, ThF showed a stronger inhibitory effect on aromatase than EGCG (Way et al. 2004). Therefore, the significantly lower mean EGCG intake for rural women compared with urban women $(P=0.03)$ may explain the lack of association between EGCG and estradiol levels in rural women.

Although an increase in levels of E2, especially over the long term, may be associated with an increased risk of breast cancer, we are not aware of data which would allow the cancer risk associated with increased E2 levels to be estimated. However, the differences we observed in the mean levels of E2 for women characterized by low and high tea consumption may allow differences in the probability of conception to be estimated. For example, the E2 levels for urban women were almost $33 \%$ higher for the group with low 'total' tea consumption compared to the group with high consumption. Based on estimates from the logistic regression curve developed from conception research (Lipson \& Ellison, 1996), such an increase in E2 levels would be associated with an almost three fold increase in the probability of conception (Jasienska et al. 2004).

In conclusion, we demonstrated that drinking tea can decrease E2 concentrations. This lowering effect was observed in our total study group but remained pronounced only for urban women, who tended to drink more tea in general and more green tea in particular, than rural women. The main strength of the present study was the precise assessment of E2 concentration across the menstural cycle based on daily collection of saliva samples combined with frequent dietary assessment. Most other studies use a single blood sample to characterize hormone levels.

\section{Acknowledgements}

We are grateful to Dr Susan F. Lipson, Dr Mary O'Rourke and Dr Diana Sherry, to the women who participated in this study and students of the Faculty of Public Health, Jagiellonian University who worked as research assistants. This project was supported by grants from the State Committee for Scientific Research, Warsaw, Poland, project no. 3 P05E 01625 and 6 P05D 112 20, the Radcliffe Institute of Advanced Study, Harvard University and the Norwegian Cancer Society.

\section{References}

Ainsworth BE, Haskell WL, Whitt MC, et al. (2000) Compendium of physical activities: an update of activity codes and MET intensities. Med Sci Sports Exerc 32, Suppl., S498-S516.

Arts IC, var de Putte B \& Hollman PC (2000) Catechin contents of food commonly consumed in the Netherlands, 2 . Tea, wine, fruit, juices and chocolate milk. J Agric Food Chem 48(5), 1752-1757.

Bielicki T \& Szklarska A (1999) Secular trends in stature in Poland: national and social class-specific. Ann Hum Biol 26, 251-258.

Cassidy A, Bingham S \& Setchell KD (1994) Biological effects of a diet of soy protein rich in isoflavones on the menstrual cycle of premenopausal women. Am J Clin Nutr 60, 333-340.

Chen S, Zhou D, Okubo T, Kao YC, Eng ET, Grube B, Kwon A, Yang C \& Yu B (2002) Prevention and treatment of breast cancer by suppressing aromatase activity and expression. Ann $N$ $Y$ Acad Sci 963, 229-238.

Conley A \& Hinshelwood M (2001) Mammalian aromatases. Reproduction 121, 685-695.

Ellison PT \& Lager C (1986) Moderate recreational running is associated with lowered salivary progesterone profiles in women. Am J Obstet Gynecol 154, 1000-1003.

Gittes RF (1991) Carcinoma of the prostate. N Engl J Med 324, $236-245$.

Hertog MG, Hollman PC, Katan MB \& Kromhout D (1993) Intake of potentially anticarcinogenic flavonoids and their determinants in adults in The Netherlands. Nutr Cancer 20, 21-29.

Jasienska G \& Ellison PT (1998) Physical work causes suppression of ovarian function in women. Proc Rl Soc Lond B 265, 1847-1851.

Jasienska G \& Ellison PT (2004) Energetic factors and seasonal changes in ovarian function in women from rural Poland. Am J Hum Biol 16, 563-580.

Jasienska G \& Thune I (2001) Lifestyle, hormones, and risk of breast cancer. $\mathrm{Br}$ Med J 322, 586-587.

Jasienska G, Thune I \& Ellison PT (2000) Energetic factors, ovarian steroids and the risk of breast cancer. Eur J Cancer Prev 9, 231-239.

Jasienska G, Ziomkiewicz A, Ellison PT, Lipson SF \& Thune I (2004) Large breasts and narrow waists indicate high reproductive potential in women. Proc R Soc Lond B 271, 1213-1217.

Jasienska G, Ziomkiewicz A, Gorkiewicz M \& Pajak A (2005) Body mass, depressive symptoms and menopausal status: an examination of the 'Jolly Fat' hypothesis. Womens Health Issues 15, 145-151.

Jasienska G, Ziomkiewicz A, Thune I, Lipson SF \& Ellison PT (2006) Habitual physical activity and estradiol levels in women of reproductive age. Eur J Cancer Prev (In the Press).

Joensuu H, Ejlertsen B, Lonning PE \& Rutqvist LE (2005) Aromatase inhibitors in the treatment of early and advanced breast cancer. Acta Oncol 44(1), 23-31.

Kapiszewska M, Zajac G, Kalemba M \& Soltys E (2005) The estrogenic status and the COMT genotype of female blood donors influence the protective ability of the Mediterranean plant extracts against the hydrogen peroxide-induced DNA damage in lymphocytes. J Physiol Pharmacol 56, Suppl. 1, 199-217.

Key T, Appleby P, Barnes I \& Reeves G (2002) Endogenous sex hormones and breast cancer in postmenopausal women: reanalysis of nine prospective studies. J Natl Cancer Inst 94, 606-616.

Kumar NB, Cantor A, Allen K, Riccardi D \& Cox CE (2002) The specific role of isoflavones on estrogen metabolism in premenopausal women. Cancer 94, 1166-1174.

Lakenbrick C, Lapczynski S, Maiwald B \& Engelhardt UH (2000) Flavonoids and other polyphenols in consumer brews of tea and other caffeinated beverages. J Agric Food Chem 48(7), $2848-2852$.

Laska-Mierzejewska T (1995) Age at menarche as an indicator of the socieconomic situation of rural girls in Poland in 1967, 1977, and 1987. Am J Hum Biol 7, 651-656. 
Laska-Mierzejewska T \& Olszewska E (2004) The maturation rate of girls living in rich and poor rural regions of Poland before and after the transformation of 1989. Homo 55, 129-142.

Lee HP, Gourley L, Duffy SW, Esteve J, Lee J \& Day NE (1991) Dietary effects on breast-cancer risk in Singapore. Lancet 337, 1197-1200.

Lee MJ, Prabhu S, Meng X, Li C \& Yang CS (2000) An improved method for the determination of green and black tea polyphenols in biomatrices by high-performance liquid chromatography with coulometric array detection. Anal Biochem 279, 164-169.

Lipson SF \& Ellison PT (1996) Comparison of salivary steroid profiles in naturally occurring conception and non-conception cycles. Hum Reprod 11, 2090-2096.

Liu Y, Gold EB, Lasley BL \& Johnson WO (2004) Factors affecting menstrual cycle characteristics. Am J Epidemiol 160, $131-140$.

Lu LJ, Anderson KE, Grady JJ \& Nagamani M (1996) Effects of soya consumption for one month on steroid hormones in premenopausal women: implications for breast cancer risk reduction. Cancer Epidemiol Biomarkers Prev 5, 63-70.

Lu LJ, Cree M, Josyula S, Nagamani M, Grady JJ \& Anderson KE (2000) Increased urinary excretion of 2-hydroxyestrone but not 16alpha-hydroxyestrone in premenopausal women during a soya diet containing isoflavones. Cancer Res 60, 1299-1305.

Mueck AO, Seeger H \& Lippert TH (2002) Estradiol metabolism and malignant disease. Maturitas 43, 1-10.

Nagamani M, McDonough PG, Ellegood JO \& Mahesh VB (1979) Maternal and amniotic fluid steroids throughout human pregnancy. Am J Obstet Gynecol 134, 674-680.

Nagata C, Takatsuka N, Inaba S, Kawakami N \& Shimizu H (1998) Effect of soymilk consumption on serum estrogen concentrations in premenopausal Japanese women. J Natl Cancer Inst 90, $1830-1835$.

Park OJ \& Surh YJ (2004) Chemopreventive potential of epigallocatechin gallate and genistein: evidence from epidemiological and laboratory studies. Toxicol Lett 150, 43-56.
Rietveld A \& Wiseman S (2003) Antioxidant effects of tea: evidence from human clinical trials. J Nutr 133, 3285S-3292S

Rosenberg Zand RS, Jenkins DJ \& Diamandis EP (2002) Flavonoids and steroid hormone-dependent cancers. J Chromatogr B Analyt Technol Biomed Life Sci 777, 219-232.

Satoh K, Sakamoto Y, Ogata A, Nagai F, Mikuriya H, Numazawa M, Yamada K \& Aoki N (2002) Inhibition of aromatase activity by green tea extract catechins and their endocrinological effects of oral administration in rats. Food Chem Toxicol 40, 925-933.

Seow A, Shi CY, Franke AA, Hankin JH, Lee HP \& Yu MC (1998) Isoflavonoid levels in spot urine are associated with frequency of dietary soy intake in a population-based sample of middle-aged and older Chinese in Singapore. Cancer Epidemiol Biomarkers Prev 7, 135-140.

United States Department of Agriculture (2003) USDA database. http://www.nal.usda.gov/fnic/foodcomp.

Verkasalo PK, Thomas HV, Appleby PN, Davey GK \& Key TJ (2001) Circulating levels of sex hormones and their relation to risk factors for breast cancer: a cross-sectional study in 1092 preand postmenopausal women (United Kingdom). Cancer Causes Control 12, 47-59.

Way TD, Lee HH, Kao MC \& Lin JK (2004) Black tea polyphenol theaflavins inhibit aromatase activity and attenuate tamoxifen resistance in HER2/neu-transfected human breast cancer cells through tyrosine kinase suppression. Eur J Cancer 40, 2165-2174.

Wenger NK (2004) Diet and exercise for perimenopausal women lifestyle interventions can decrease cardiovascular risk. $J$ Am Coll Cardiol 44, 586-587.

Willer A (2003) Reduction of the individual cancer risk by physical exercise. Onkologie 26, 283-289.

Wu AH, Stanczyk FZ, Hendrich S, Murphy PA, Zhang C, Wan P \& Pike MC (2000) Effects of soy foods on ovarian function in premenopausal women. Br J Cancer 82, 1879-1886.

Zografos GC, Panou M \& Panou N (2004) Common risk factors of breast and ovarian cancer: recent view. Int J Gynecol Cancer 14, $721-740$. 